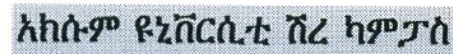

qnas hase

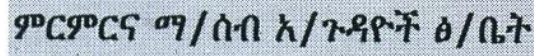

ه 314

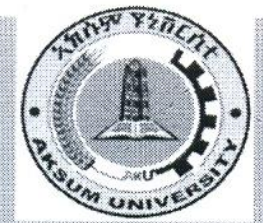

Aksum University Shire Campus College of agriculture Research \& community service affairs

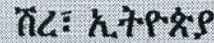

Shire, Ethiopia

Date: 02 May 2016

\title{
To Whom It May Concern
}

\section{Ref: Confirmation of Ethical Clearance}

The Research and Ethics Review Committee (RERC) of Aksum University Shire Campus has critically evaluated the scientific and ethical aspects of the research proposal titled "Incidence of Human Rabies Exposure in North western Zone of Tigray, Ethiopia" to be conducted by Dr. Gebreyohans Gebru and Teweldemedhn Gebretinsae at Suhul Hospital of Shire Endaselase. Thus the committee has approved the proposal on the following conditions:

1. An official letter must be issued to Suhul Hospital to aware that the findings would be used for scientific purposes and must agree to provide the research data,

2. The comments forwarded are fully addressed,

3. The hospital must provide letter of confirmation about the data given to the researchers and

4. The research and community service officer makes sure that the research is conducted according to the approved proposal.

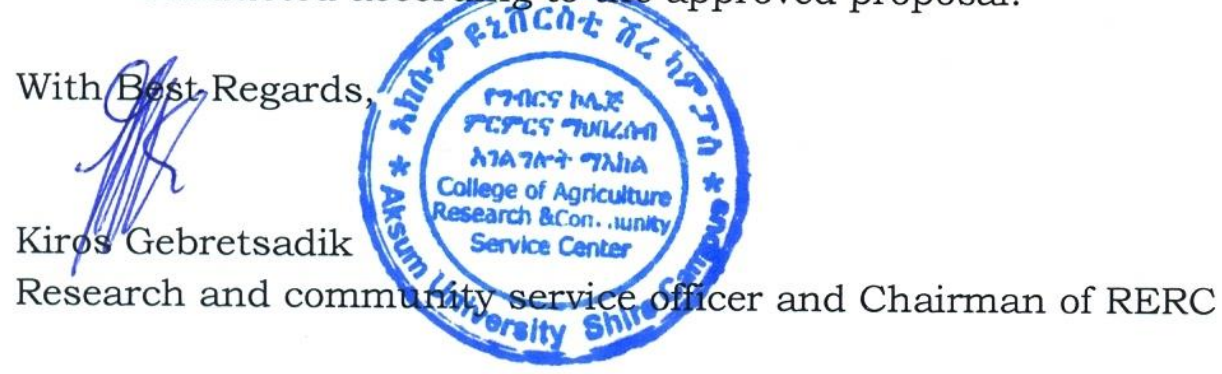

